\title{
Scientific and associated engineering technology and technical excellence
}

Technical excellence is a requirement for good technology development concerning all scientific and associated engineering disciplines, including for example Geoscience, Climate Studies, Global Warming, Meteorology, Hydrology, Earth Science Research, Thermodynamics of Earth and Atmosphere, Natural and Man-Made Hazards. It should be the goal of all scientific and engineering organizations and individuals, whether in government or private industry, national or international. What do we mean by technical excellence? Most people have their own ideas and interpretation as to what constitutes technical excellence. ${ }^{1}$

Since the intent of this article is to address the importance of technical excellence relative to the development of scientific and associated engineering technology, it may be good to explore a few statements that have been made by some key individuals who were in the aerospace community. One author, Teresa Vanhooser, ${ }^{2}$ defined technical excellence as an effort to ensure that well-considered and sufficient technical thoroughness and rigor are applied to programs and projects under an uncompromising commitment to safety and mission success. A NASA Associate Administrator, Chris Scolese, ${ }^{3}$ identified four guiding principles to achieving technical excellence.

a. Clearly documented policies and procedures

b. Effective training and development

c. Engineering excellence

d. Continuous communications

According to Scolese, two fundamental attributes must be considered when pursuing technical excellence: personal accountability, whereby each individual must understand and believe that he or she is responsible for the success of the organization's mission, and organizational responsibility, whereby the organization provides the proper training, tools, and environment. ${ }^{4}$

Louis Armstrong, a famous trumpet player, is understood to have remarked, "If you have to ask what jazz is, you will never know". This remark also applies to technical excellence when one tries to quantify its meaning by producing metrics to establish whether a particular objective or goal has been achieved. For example, what provides a measure of the technical excellence achieved by an organization and its scientific and associated engineering staff? Number of patents received? Number of professional scientific and associated engineering journal publications? Number of individuals with advanced degrees? Number of scientists and associated engineers versus non-scientists and associated engineers in an organization? Positive versus negative feedback on scientific and associated engineering staff publications? Equipment, instruments or associated system successes versus failures? Profits a company makes?

In the aerospace arena, one can certainly equate organizational technical excellence, and thus good technology, with mission success, at least in the eyes of the public and in the eyes of Congress. In the final analysis, technical excellence is one of the most important
Volume 4 Issue I - 2020

\author{
William WVaughan \\ NASA's George C. Marshall Space Flight Center, USA
}

Correspondence: William WVaughan, George C. Marshall Space Flight Center, NASA Emeritus, Alabama, USA, Email william.w.vaughan@nasa.gov

Received: February 13, 2020 | Published: April 30, 2020

goals of any aerospace scientific or engineering organization. How one achieves and maintains it is another question for which there is no simple answer. An organization with recognized scientific and associated engineering leaders who have vision, superior technical and scientific competence, and the desire to excel will achieve technical excellence. Thus, technical leadership is key for a scientific and associated engineering organization's success and the ability of the managers assigned to carry out the mission of the organization.

Technical excellence is also related to the strategic management of an organization's human capital. The technical excellence of its workforce is an organization's most critical asset in accomplishing its mission. Therefore, continued development of scientific and associated engineering expertise is necessary to preserve an organization's and (in the case of a government organization) the nation's role as a leader in scientific and engineering technology development.

In an attempt to identify a few outstanding characteristics of managers or management approaches that would ensure a program's success, NASA after completing the very successful Saturn-Apollo program, undertook a research study in 1974. The study identified three "tall poles" important to program management. "Pay attention to detail." (By George M. Low); "Leave no stone unturned", (By Wernher von Braun), and "Be aggressive." (By Lee B. James) These characteristics create policies and management methods that are highly conducive to a program's scientific and engineering success plus associated systems engineering ${ }^{5}$ or, in other words, successful technology development and management. ${ }^{6}$

\section{Acknowledgments}

None.

\section{Conflicts of interest}

Author declares that there is no conflict of interest.

\section{References}

1. Gill PS, Vaughan W. Technical Excellence: A Requirement for Good Engineering. 46th AIAA Aerospace Sciences Meeting and Exhibit: Reno, Nevada; 2008.

2. Vanhooser T. MSFC Technical Excellence/Technical Authority. NASA Marshall Space Flight Center: Huntsville, AL; 2007. 
3. Scolese C. Four Guiding Principles of Technical Excellence. ASK OCE 2006;1(4).

4. Scolese C. Technical Excellence: Roles and Responsibilities. ASK OCE. 2006;1(5).

5. Vaughan W. Systems Engineering. Journal of Aerospace Technology and Management. 2016;8(2):121.
6. Dannenberg KK. Management Philosophies as Applied to Major NASA Programs, N75-14633. University of Tennessee Space Institute: Tullahoma, TN; 1974. 